\title{
Software Development Technique for the Betterment of End User Satisfaction using Agile Methodology
}

\author{
Lalband Neelu ${ }^{1}$, D. Kavitha ${ }^{2}$ \\ ${ }^{1}$ Research Scholar, Dept. of C.S.E, JNTUA, Anathapuram, India \\ ${ }^{2}$ Professor, Dept. of C.S.E, G. Pulla Reddy Engineering College, Kurnool, India
}

\begin{abstract}
Agile methodology mainly focuses on the end user priority during the each and every stage of software development process. There is a huge scope in this technique in order to alter the major/minor modifications at each stage of software development for attaining the customer satisfaction. The main aim of the present work is to compare agile methodology with the traditional system methodologies. The present state of using the agile technologies for customer satisfaction at every phase by delivering valuable software continuously is also discussed in the present work. Based on the pitfalls in the existing models, a new model is proposed here in the present study.
\end{abstract}

Keywords - Agile software development, Traditional software models, Lean, Scrum, XP

\section{Introduction}

Agile software development reduces the software life cycle time by integrating the functionality on iterative basis by creating a prototype version for responding the customer prerequisites and testing all through the software development process cycle. The evolution of agile methods is due to the inabilities of technical environment with the lack of

DOI: 10.18421/TEM93-22

https://doi.org/10.18421/TEM93-22

Corresponding author: Lalband Neelu, Research Scholar, Dept. of C.S.E, JNTUA, Anathapuram, India.

Email: neelu.lalband@gmail.com

Received: 27 March 2020.

Revised: 07 August 2020.

Accepted: 12 August 2020.

Published: 28 August 2020.

(cc)BY-NC-ND(C) 2020 Lalband Neelu \& D. Kavitha; published by UIKTEN. This work is licensed under the Creative Commons Attribution-NonCommercial-NoDerivs 4.0 License.

The article is published with Open Access at www.temjournal.com communication from the client end at the early stage of project especially in defining the requirements properly.

To overcome the problems facing the industries, software and project developers are working towards the development of software methodologies and come up with a technique called Agile Methodology. Agile method is very good at adapting the contextual changes with the specifications during any stage of the software development process. Agile methodology mainly focuses on the end user priority during each and every stage of software development stage. Utilizing the Agile methodology attains better results in terms of end software product during every stage of Software Development Life Cycle (SDLC). Evolution of agile methodologies started during 1990's over the drawbacks like heavy documentation, simplicity and lack of productivity in traditional methods [1].

Agile software development process is combination of methods, techniques and activities, which are usually utilized to develop and guarantee the software related products. The major issues arise in the software industries are discussed by the software developers regarding faster delivery and cheaper cost with better performance. To overcome these issues, the Agile methodology evolves in midnineties with many principles like SCRUM [2], eXtreme Programming (XP), Crystal and Feature Driven Development (FDD) etc. Fig. 1. shows the agile software development cycle.

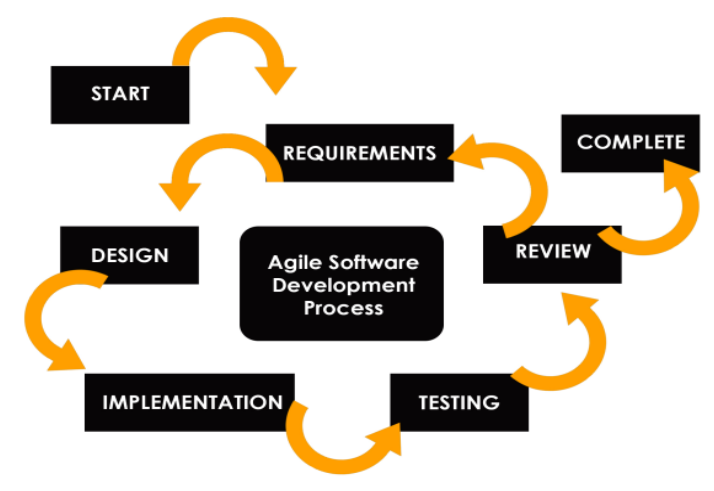

Figure 1. Agile Software Development Process [3] 


\section{Literature Review}

The basics of agile started when the researchers tried to separate the principles of design, implementation and testing by incremental and iterative development methods during the nineteenth century. The implementation of the agile method was described by inventions of codes and functional groups with certain intermediate check points for validation and verification of the developed codes against the end product. Later, evolutionary project management evolved with incremental and iterative developments as the key practices. To cut short these techniques, researchers thus breakdown the systems into various small sub groups each having their own importance and specific goal. All sub groups are clubbed together to get the larger goal with provision of retreatment [4].

To be frank there are many agile methodologies with their own specific principles and rules, but only few are into existence based on their advantages over the applications. The common principles in all these agile methodologies are business problems. These methodologies develop solutions for the particular problem with in the stipulated time based on the dynamic changing characteristics of the end user. In agile methodology, communication is highly recommended whereas the process is not much concentrated on any type of teams. Agile solves the problem based on the customer requirement and the demand of the end user. It concentrates less on the management aspects, quite few concentrates more on the practices of the software development. There are also many differences in the agile methods since the coverage of the software development cycle phase's changes frequently. The difference in team composition and their efficiency are the major factor to be considered in agile methods for a specific function.

Agile software development works as a group of development methodology to encourage the improvements of iterations, development of flexibility and open team work throughout the project development. It basically divides the projects into small groups with only nominal planning such that the risk of failure is minimized and changes can be implemented in a rapid pace. To implement the changes in the project development, customer involvement is considered as mandatory in software development.

Almost all the agile software processes are mainly differentiated by three major assumptions for any of the software projects:
1. Customer requirements will change at any time, so the prediction of the software requirement in earlier stage is difficult. Therefore, it is difficult to know which software requirements are to be continued and which need to be changed.

2. Design and construction of the software are interleaved.

Agile process is adaptable since design, construction, analysis and testing are not able to predict.

Customer involvement is an important role in agile projects to force the project by means of key responsibilities with constant interaction and give requirements for business people. Moreover, customers join the test observations at the intermediate stages and fulfill their requirements. Customers may not support throughout the software development process due to the dynamic nature of the changes in the project phases. Thereby, the customers are not treated as final supporters so that some fake roles are created to support the project development in order to complete the project in a stipulated time with higher efficiency. The created fake roles are of speaker, customer trainer, any technical association, designer skill specialist, skill tester and quality tester.

Wan and Wang [5] emphasized the features of organization alertness in terms of novelty and innovation, speedy response to adjust the changes, knowledge and ideas that are necessary for the selection of agile development methodologies. In another work by Lindvall et al. [6], it is recommended that the project size, riskiness, consistency, criticality of the project are the major concerns to be considered for selection of projects in agile methodology.

\section{Agile Methods}

From the last decade, there are many agile software methodologies available for specific projects based on their requirements of the software development. As mentioned earlier, agile methods are the combination of both iterative and evolutionary techniques. Agile methods are mainly focused on the enhancement and process development. With this, the agile method advances in terms of development, collective work, relationship development and process adaptability during the project life cycle. Fig. 2. shows an agile software development methodology process flow (Scrum). 


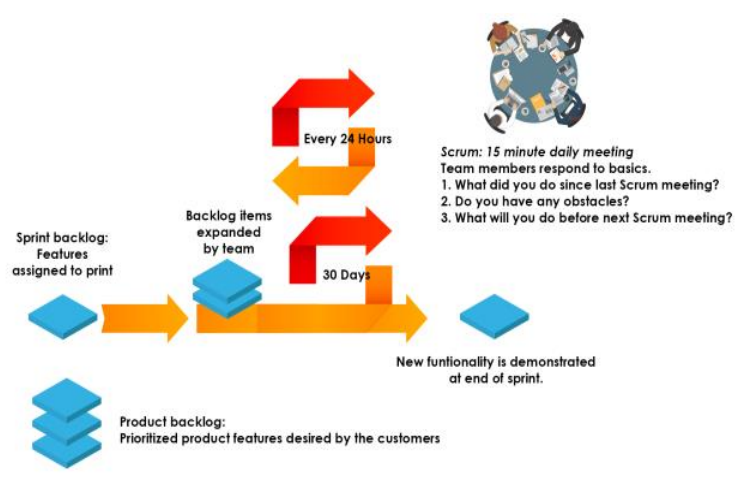

Figure 2. Scrum methodology for software development [7]

Changing of customer requirements are not quickly done using traditional software development methodologies [8]. For example in water fall model, customers were involved during the early phases of the software development, but after certain time limit customers loose connection with the developers so customers become idle and there is no role for customers in traditional software developments till the completion of the project. Due to this, the end user has no idea of what task is going on what is the end product which she is going to get. In traditional model, the developer freeze the requirements of the customer at the earlier stages of the software development, therefore there is no chance of modifying the software development at the intermediate stages.

\section{Advantages of agile method for software development:}

- Dynamic changes take place as per the customer requirements.

- Customer involvement takes place during the whole process of product development; therefore customers have an idea of what product will be delivered to them.

- Communication between customers and developers are high.

- Customers need not to wait till the completion of the project.

- Organizations assure the customers regarding the final product that they will receive after completion of the project.

- Developers can easily modify the project at any stage as per customer requirement.

- Almost all the customers feel $100 \%$ satisfaction with agile methodology.

\section{Traditional Methodology versus Agile Methodology}

In traditional software development techniques, requirement cannot be altered once the choice is finalized. In order to change the project in traditional method, the project should start from initial stage again. But, in agile methodology, background scalability iterations can be possible such that project can be altered and implemented as per the client requirement. Moreover checking of errors are possible during the initial stage of the development in the agile development process. When compared to waterfall model, agile is error free and bud free since traditional model check for error after the total completion of the project. Modifications in traditional model are difficult during the initial stage, but can be altered after the completion of the project. To change the project as per the customer requirement in traditional model the project should be started right from the beginning [10].

\section{Different types of common agile development methodologies}

Development of project be can completed in less time with cheaper cost and high quality project can be achieved by utilizing agile software development methodology [8],[9].

\section{Extreme Programming $(X P)$}

For an unstable environment conditions extreme programming methodology is mostly used. Extreme programming is used only for small teams with a size of 2 to 10 members, with an iteration round of nearly 2 weeks. XP methodology is not considered as a better option for distributed teams. There are five principles in XP development methodology. First is to maintain a good communication between the user and developer. Second is to develop the project as simple as possible. Third is to take the feedback from the customer after altering the project as per end user choice. Fourth is to encourage the customer to identify the faults in the project and finally the fifth one is to ask the customer with full respect to come up with new requirement. XP focuses mainly on the customer satisfaction by allowing the flexibility to alter the modeling process. The main aim of the XP is to diminish the cost of changing the project at the earlier stage of project development since the traditional software development freezes the rules at the beginning of the project itself [10]. Changing the project at the later stage involves high costs [8]. So, therefore, XP evolves as the first agile process which contains a group of individual projects and that make together with large projects [11]. 


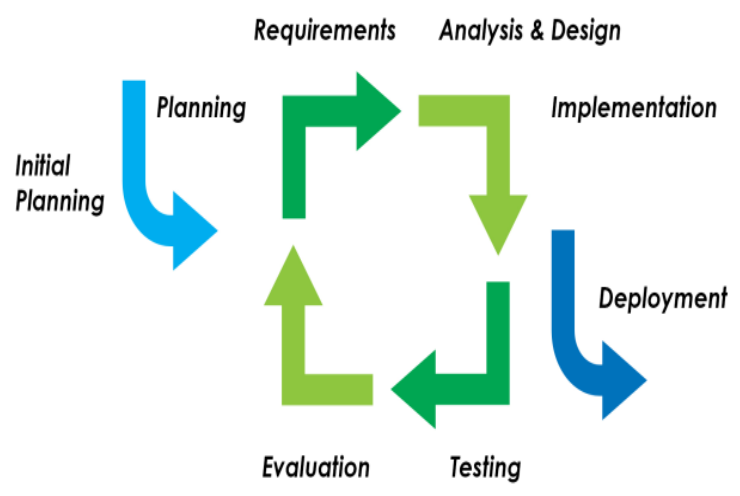

Figure 3. Iterative and incremental agile development process [11]

Total application is divided into sub groups called iterations and the development time of each subgroup is less (mostly within a weeks). Present iteration of the project will take information from the previous iteration to build the project, such that this agile methodology with these sub groups offers rapid software improvement with high visibility and motivation. Traditional approach is completely different from agile methodology when compared to the project completion and visibility.

B. Bahli and ESA Zeid [12] compared the traditional waterfall model with XP for the development of project and observed that waterfall model produced an unpleasant understanding when compared to XP and found advantages for the management side. XP has a drawback of delivering the project by $50 \%$ late when compared to traditional project by $60 \%$, but overall XP reduces the cost of the project by $25 \%$. Agile methodology reduces the cost of the project mostly at management and documentation if at all a rework of software development has taken place. Fig. 4. shows the comparison of agile methodology with traditional approach on the cost aspects of the project.

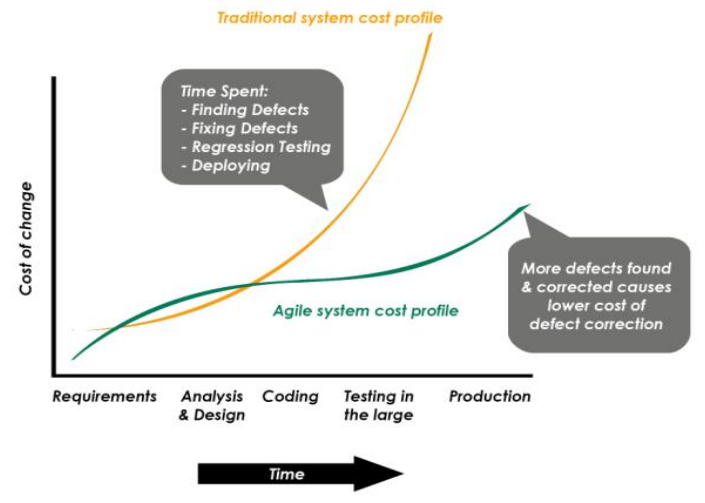

Figure 4. Comparison of traditional and agile software development costs (Source: http://www.thoughtworks.com)

Planning: Planning is one of the most important phases in order to predict the cost and man power requirements for the software development. The planning is compulsory for the project development since the development of the project is visible everywhere at any time during the software development. The planning in XP methodology is divided into two phases:

Release planning: Initially before starting of the project client explains all the necessary features required from the project to the developer and expects what is going to be delivered at the end of the project completion. The developer analyzes all the features which were explained by the client and identifies the problems which may arise during the project development. Based on the analysis of the developer, the initial release for the project development takes place.

Iteration planning: The project is divided into small groups with each group having a limited time of weeks. After completion of each group task, the customer checks the process and communicates with the developer to alter the project if necessary or else proceed further for the next iterations (groups).

\section{Feature Driven Development (FDD):}

Feature driven development is considered as the backbone for the software development and focuses more on the characteristic of the software system.

- The detailed form of the arrangement was constructed during the initial stages of the FDD by assuming all the requirements of the clients.

- Each feature has to be developed within a stipulated time which is not more than 2 weeks. Once the model is built, team members try to work on the system features of the domain model.

- Each group of team works parallel to each other to develop all the necessary features.

- FDD mainly detect the defects with strict rules by implementing certain codes and is able to alter the features of the model on a weekly basis.

- Integration of all the features of the software development requires parallel developments of the groups to maintain the management system in a proper arrangement [10].

B. Boehm [13] investigated the changing requirements and its manageability of both traditional and agile approaches. The changing requirements are turbulent in nature as these are adaptive in nature and emerge rapidly when compared to the pre-specified approaches. From the work, it was concluded that the agile approaches respond to the changes rapidly in terms of planning, development and delivery with high flexibility in changing the project. Fig. 5. represents the comparison of agile and traditional approach in manageability of the changing requirements. Fig. 6. shows the changing cost of development process for both agile and traditional approaches. 
In agile methodology, both the clients and developers have the right to change the project at point of time but the ultimate right to approve the change is only within the client. Changing the project in traditional approach is a tough task in most of the cases, in fact it is not at all possible. Moreover, if the change of the project is possible in traditional approach, the cost and delivery time increases.

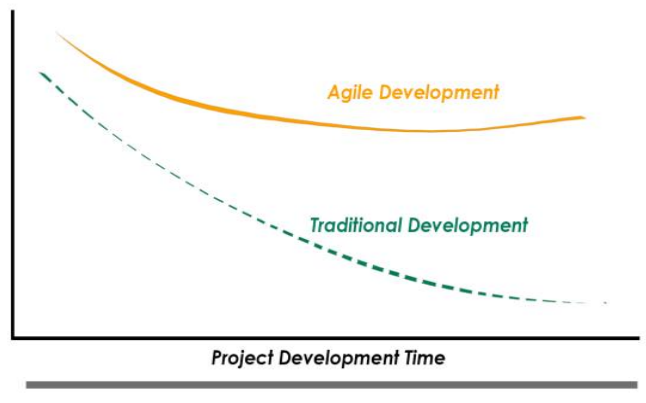

Manage ability based on changing requirements

Figure 5. Comparison of agile and traditional requirements change management (Source: $\underline{w w w . v e r s i o n o n e . c o m)}$

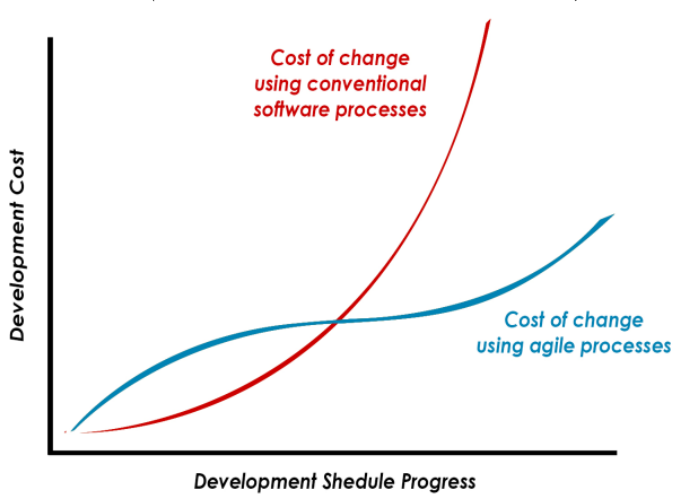

Figure 6. Cost of change for agile and traditional software development process

\section{Crystal}

Alistair Cockburn developed the crystal methodology and is considered as an adaptable and lightweight approach for software development. Crystal methodology is used for small projects with a team of around 10 members [8]. Crystal methodology is a part of agile methodology with different crystal colors like yellow, red, orange diamond, sapphire and crystal clear as well. Crystal methodology has an ability to adopt easily with faster delivery times, high customer involvements and elimination of defects easily when compared to other agile approach [10].

\section{SCRUM}

The concept of scrum was first applied by Ken Swaber in the year 1995. Scrum is mostly used to build up the tiny and difficult projects [8] and this framework is also considered as a light weight method for the software development. It is mostly useful for the developers to check the iterations after every task because these framework contains lightweight method such that the alterations in the project can be easily applied. Release of small iteration for the software is called sprints. Scrum is mostly used in the software development since it creates high revenue with best results [10]. The size of iteration in scrum is around 1-6 weeks. Even in this scrum method, there are also small teams to support the distributed teams. So each team is called sprint for the development of projects. Each sprint creates individual work for software development. The next step in the software development phase continues only after the completion of the previous phase [2]. Client involvement is necessary for creating the backlog features for further improvements. The backlogs specified by client will become the sprint planning meeting and priorities are kept at top for important tasks and least important tasks are kept at the bottom.

Customer involvement is very high in agile methodology when compared to traditional methods; active involvement of the customer is shown in Fig. 7. Customer involvement in agile method leads to face to face interaction with developer and provides a feedback at every stage of the project. The customer in the agile method should be committed and knowledgeable since the feedback from the customer is highly required during the project development [13], due to the fact that customer direct involvement documentation is not much required in this method.

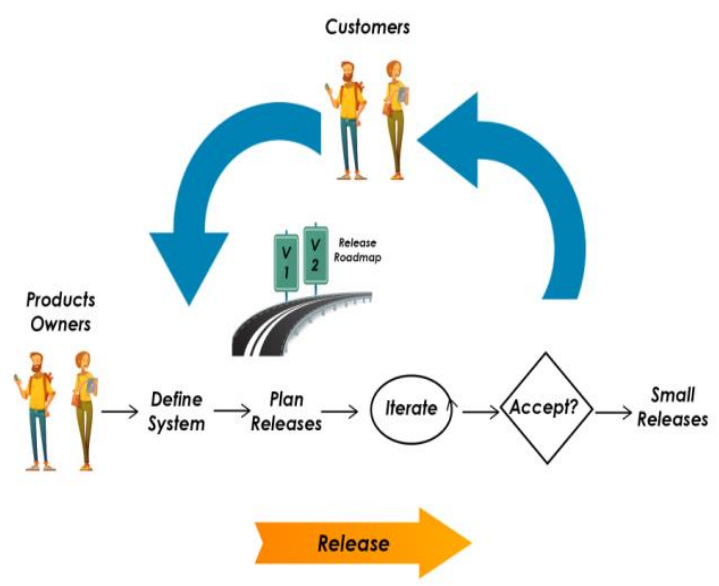

Figure 7. Customer involvement in agile approach

The difference in both traditional and agile methods of customer involvement is shown in Fig. 8. Traditional method follows big design up front technique with which the developments in design are modified in early stages as shown in Fig. 8. In traditional method, the feedback from the clients is taken after the completion of sixty percent of the phases in project development. 


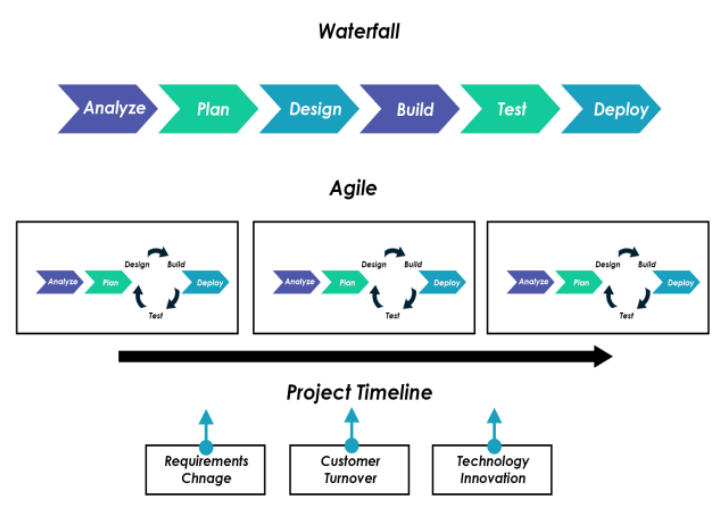

Figure 8. Composition of design phase for both waterfall and agile development

Sprint planning: Sprint planning meeting plans the tasks to be carried out in the next sprint. The planned tasks will help the developers to estimate the time requirement for project completion. The team members select the work which was asked in the sprint planning and send it to sprint backlog.

The responsibility of the team members is to deliver the functional requirements by deciding the necessity of iterations. All the members work together in a cooperative background. In agile method, team decides the required manpower for the project completion based on the project complexity and delivery time [14].

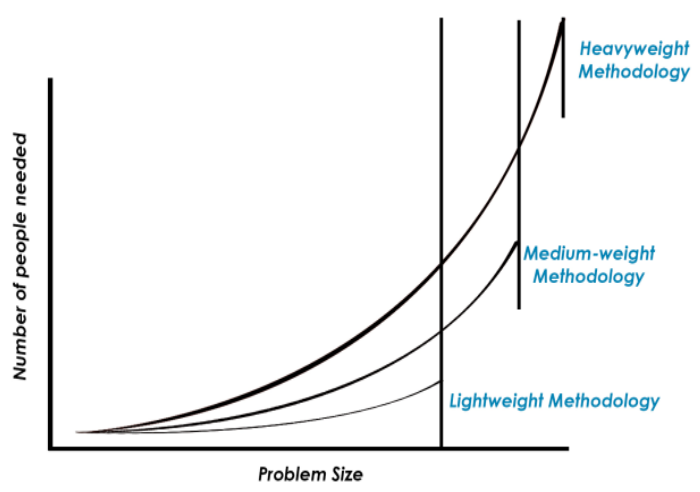

Figure 9. Estimation of team size based on problem size [14]

Product backlogs: The priority order of the works is taken care first in product backlogs. In this, all the features must be understood based on its functionality. Planning before execution of the project is the main motto of the meeting. After this, the scrum team comes, meets every day, to discuss the tasks completed for the day and the plan of works to be carried out in the coming day. Scrum meetings help the developers to improve the project completion and estimate the project time required with proper observation of the errors in the project.
The three major roles in the scrum process:

Product owner: Product owner/client is the major responsible in project development as he/she communicates between the developer and the client. The communication leads to increase the priority of the project requirements and reduces the project delay since project owner will be the sole responsible for managing the project module.

Scrum master: The role of the scrum master is to provide the requirements for the project team to develop the project and the required information for the project owner as well. Scrum master acts as a facilitator by managing both the client and team members such that the obstacles for the project development can be reduced [2].

Team member: The responsibility of the team members is to work for the software development and complete the task in required time. Actually the team members are a group of seven different cross functional members based on their skill and specialization. The different skills required for the project development are software engineers, architects, UI designers, analysts, programmers, QA experts and testers. The responsibility of all these members is to complete the project in specified time by applying their full efforts [10].

The motto of the sprint review is to check the product quality by showing the final product to the client and project owner. The feedback from both will be taken into account for further development of the product [10]. Later, the sprint retrospective tracks the sprint project blockings and solves the problems. As per the literature studies, nearly $70 \%$ of the projects fails in terms of cost, project delivery and features especially in traditional methods. Agile overcome these pitfalls and increase the rate of project success in terms of user acceptance, cost and timely delivery of the project. Risk management is almost reduced even after the implementation of changes in the project as per the agile methodology as shown in Fig. 10 [15].

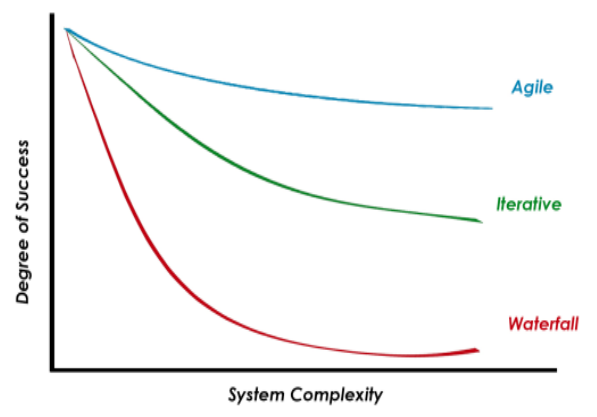

Figure 10. Degree of success for various software development methods 
Report of CHOAS in the year 2000 [16], shows that the $25 \%$ of the project cancellation takes places without software deployment, but after implementing the agile methodology, the statics is changed as is observed from the Fig. 11.
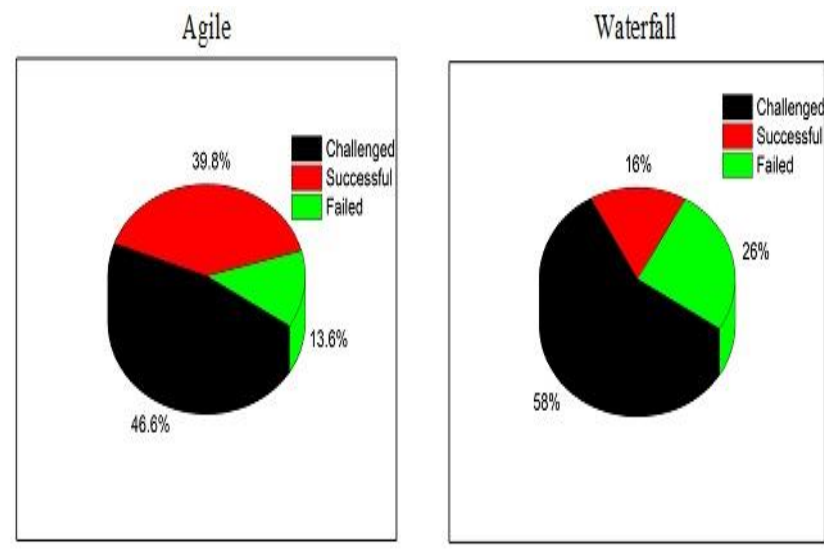

Figure 11. Success rate by agile implementation

\section{Existing Models}

Many initiatives are being taken by organizations so as to advance the present software development methodologies, but have not obtained fruitful results. Most of the organizations have utilized their own developed methodologies instead of formal software methodologies [17-18]. The reasons for not utilization of the formal methodologies are due to the lack of adjustable, suitable and eligible methodologies by the organizations based on the project requirements [19], [20]. Many other reasons there are such as not suitability of the specific characteristics for the adoptability of formal methodologies as per the project development teams [21],[22],[23],[24]. The success of the project includes the scope, time and cost of the project for all the traditional methodologies. In the recent studies, a Project Management Body of Knowledge (PMBOK 4.0) was implemented based on the six significant factors for the success of projects [25],[26],[27]. All the recently developed software development models showed significant improvements in quality, process visibility, time boxing and successful customer involvement along with project management [28]. One among such models is the A-Z model which possess all the above mentioned improvements.

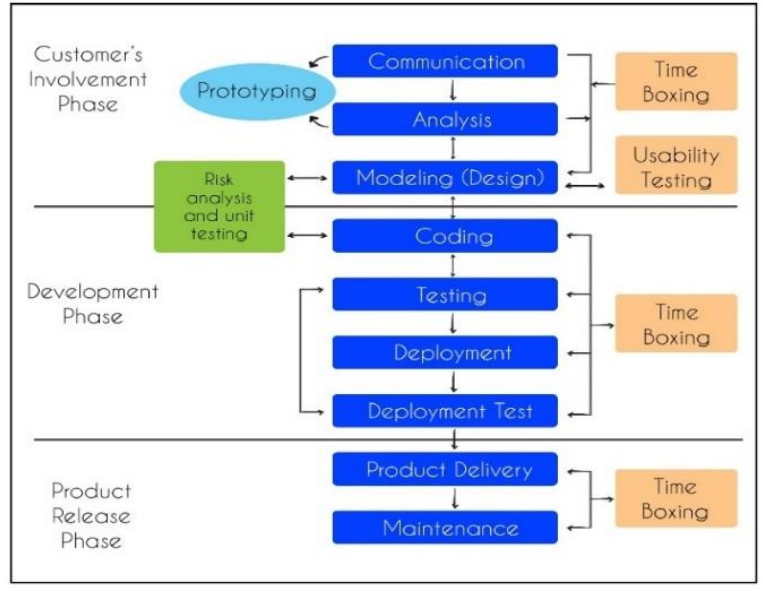

Figure 12. A-Z project development workflow diagram

\section{Agile Adoption}

Project success rate is increased rapidly by the implementation of agile methodology [17]. The increase in success rate of agile methodology is highly adaptive in nature [18]. The adoption of agile in software industries is shown in Fig. 13. From Fig. 13 , it is observed that the industries implemented agile have a success rate of $71 \%$ but where as $15 \%$ of the industries have no success in their project even after the implementation of the agile methodology.

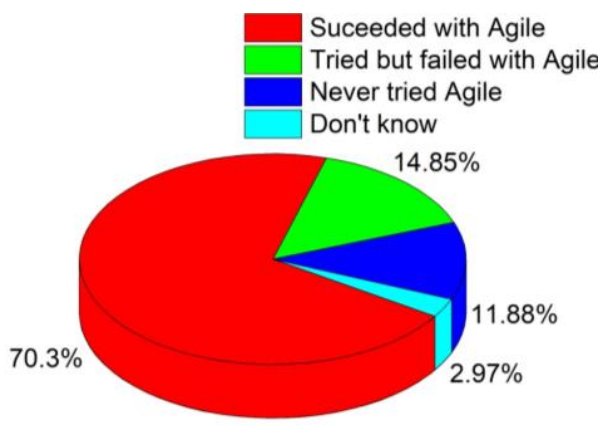

Figure 13. Adoption of Agile and its success rates (Source: http://www.ambysoft.com/surveys)

\section{Proposed Model}

The proposed study involves an improvement of the existing software development methodologies based on the opinions of the various techies from the software organizations. The developed model was successfully implemented by the organizations. Likewise; A-Z models, the present developed model 
also consists of three phases. First is development phase in which the prototype is developed. Till the end of the first phase, customer involvement is made mandatory and the stakeholder will alert the software engineers if they observe any deviation from the project. The second stage is the implementation phase in which the testing of the developed code will be taken care of. Based on the developed code, the deviation in the project can be predicted and suitable measures will be implemented. In this phase, technical personnel is involved who is appointed by the stakeholder in order to observe the project implementation as the stakeholder may or may not be understood during the software development process. The main aim of this technical personnel is to observe the process and suggest the suitable measures in order to reduce the failures of the project. The final stage is the project release phase in which the project is reviewed thoroughly by the coders, developers along with the testers who are involved during the project development and implementation process before delivery of the project to the customer. For each and every phase, a time boxing schedule is fixed based on the tasks involved in the project. After completion of each phase, the estimated time and implemented time is compared and analyzed, and furthered in the process. Based on the difference, the prior reasons were submitted to the project manager in order to implement for the upcoming projects.

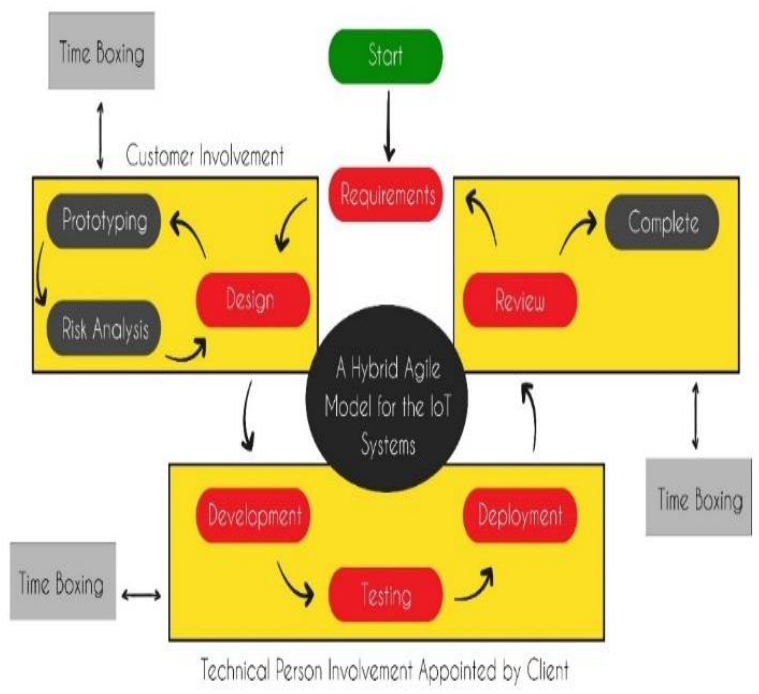

Figure 14. Proposed software development model
Techniques used for various stages of proposed software development systems are shown in Table 1.

Table 1. Phases in development of the IoT system and agile techniques

\begin{tabular}{|l|l|}
\hline $\begin{array}{l}\text { Phases in Development of } \\
\text { System }\end{array}$ & Agile Techniques \\
\hline $\begin{array}{l}\text { Objective/ Scope of the } \\
\text { System }\end{array}$ & Scrum \\
\hline Requirement and Analysis & XP/ Scrum \\
\hline Design Analysis & Lean \\
\hline Coding/ Implementation & $\mathrm{XP}$ \\
\hline Testing & $\mathrm{XP}$ \\
\hline Deployment/Maintenance & Scrum / XP \\
\hline
\end{tabular}

In the past system, development was just stopped after the release of the product worldwide. Now systems are not built in such a way, moreover traditional models are not suitable for market change and extending. If we consider the IoT systems, we cannot just deploy it and stop it. Post deployment and updates are in need for the IoT systems, which is easily possible by navigating the systems with agile techniques. To satisfy user desires, frequent updates and continuous deliveries are essential. Business requirements will be continuously changing and they should be manageable according to schedules and time to the market, which is possible by scrum management. Agile techniques also support automation of software, from building; testing and deploying different tools are used. The main drive to use automation tools is to reduce risk, security flaws, for a better and stable end product done by testing. The development time is also reduced during software updates and new features to the next release.

The proposed model is successfully implemented in three organizations and the feedback from the employees was collected. The questionnaire was prepared which consists of simple 8 questions as mentioned in Table 2. Table 3. represents the Likert scale numerical values for the developed questionnaire. A total of 25 employees responded out of 30 employees with a response rate of $83.3 \%$. The detailed analysis of the respondents was shown in Fig. 15. Fig. 15 illustrated that the organization with around 50 employees responded high when compared to the organization with more than 50 employees. 
TEM Journal. Volume 9, Issue 3, Pages 992-1002, ISSN 2217-8309, DOI: 10.18421/TEM93-22, August 2020.

Table 2. Questionnaire based on the present proposed model

\begin{tabular}{|c|l|c|}
\hline $\begin{array}{c}\text { S. } \\
\text { No. }\end{array}$ & \multicolumn{1}{|c|}{ Question } & Factor \\
\hline 1 & $\begin{array}{l}\text { By the proposed model, the team is } \\
\text { aware of the project status and } \\
\text { obtains satisfactory requirement } \\
\text { from the customer }\end{array}$ & Schedule \\
\hline 2 & $\begin{array}{l}\text { Project will have distinct scope by } \\
\text { this proposed model }\end{array}$ & Scope \\
\hline 3 & $\begin{array}{l}\text { The project can be completed within } \\
\text { the specified budget }\end{array}$ & Budget \\
\hline 4 & $\begin{array}{l}\text { The risk and opportunities of the } \\
\text { project by the proposed model is } \\
\text { quite manageable }\end{array}$ & Risk \\
\hline 5 & $\begin{array}{l}\text { Based on the proposed model, the } \\
\text { team can be worked altogether and } \\
\text { can utilize all the available resources }\end{array}$ & Resource \\
\hline 6 & $\begin{array}{l}\text { Overall, the quality requirement and } \\
\text { customer satisfaction will obtain }\end{array}$ & Quality \\
\hline
\end{tabular}

Table 3. Numerical response corresponding to the Likert scale for prepared questionnaire

\begin{tabular}{|c|c|}
\hline Likert scale response & Score \\
\hline Strongly agree & 1 \\
\hline Disagree & 2 \\
\hline Neutral & 3 \\
\hline Agree & 4 \\
\hline Strongly Agree & 5 \\
\hline
\end{tabular}

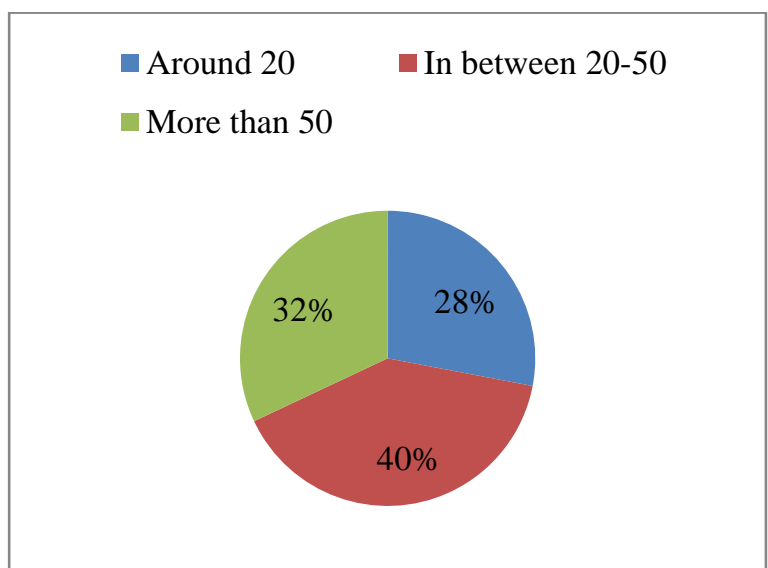

Figure 15. Response of the respondent's organization size for questionnaire

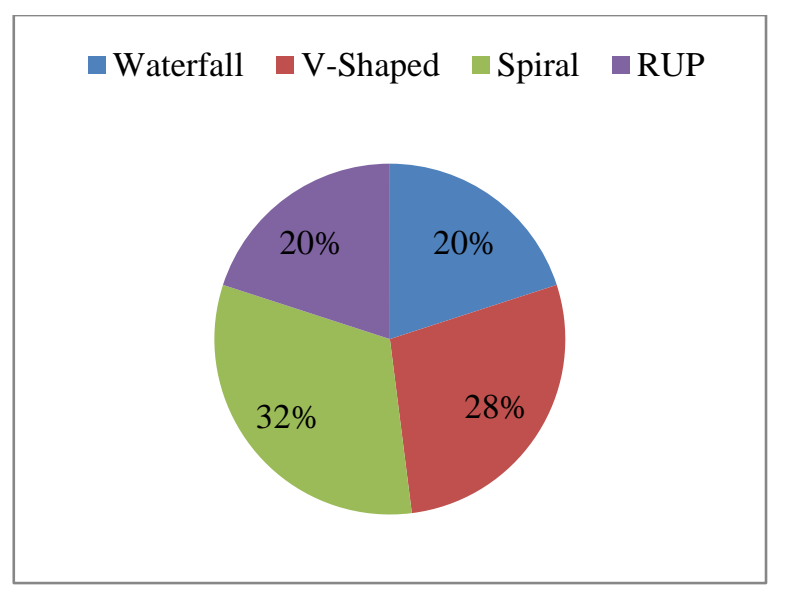

Figure 16. Previous experience in usage of other software models by the respondents 
Fig. 16. represents the experience of the respondents in usage of other latest developed software development models. Based on their experiences, it can be concluded that the present proposed model can be fully utilized and can give fair feedback on the proposed model. The questionnaire respondents consist of all the specialist members who include analysts, coders, developers, designers, testers, marketers and requirement engineers. Experiences of the respondents are also one of the prime factors to obtain fair feedback for the proposed model. The feedback was collected only from the employers whose experience is more than 3 years in the selected domain. More than $55 \%$ of the respondents had an experience of more than 5 years out of the responded 25 respondents and the summary is tabulated in Table 4.

Table 4. Summary of the survey response count

\begin{tabular}{|c|c|c|c|c|c|c|}
\hline Factor & Questionnaire & SD & D & $\mathbf{N}$ & $\mathbf{A}$ & $\mathbf{S A}$ \\
\hline Schedule & $\begin{array}{l}\text { By the proposed model, the team is aware of } \\
\text { the project status and obtain satisfactory } \\
\text { requirement from the customer }\end{array}$ & 0 & 0 & $\begin{array}{c}10 \\
(40)\end{array}$ & $\begin{array}{c}8 \\
(32)\end{array}$ & $\begin{array}{c}7 \\
(28)\end{array}$ \\
\hline Scope & $\begin{array}{l}\text { Project will have distinct scope by this } \\
\text { proposed model }\end{array}$ & 0 & $\begin{array}{c}2 \\
(8) \\
\end{array}$ & $\begin{array}{c}4 \\
(16) \\
\end{array}$ & $\begin{array}{c}8 \\
(32) \\
\end{array}$ & $\begin{array}{c}11 \\
(44) \\
\end{array}$ \\
\hline Budget & $\begin{array}{l}\text { The project can be completed within the } \\
\text { specified budget }\end{array}$ & 0 & $\begin{array}{c}2 \\
(8)\end{array}$ & $\begin{array}{c}8 \\
(32)\end{array}$ & $\begin{array}{c}7 \\
(28)\end{array}$ & $\begin{array}{c}8 \\
(32)\end{array}$ \\
\hline Risk & $\begin{array}{l}\text { The risk and opportunities of the project by the } \\
\text { proposed model is quite manageable }\end{array}$ & $\begin{array}{c}2 \\
(8)\end{array}$ & $\begin{array}{c}4 \\
(16)\end{array}$ & $\begin{array}{c}6 \\
(24)\end{array}$ & $\begin{array}{c}5 \\
(20)\end{array}$ & $\begin{array}{c}8 \\
(32)\end{array}$ \\
\hline Resource & $\begin{array}{l}\text { Based on the proposed model, the team can be } \\
\text { worked altogether and can utilize all the } \\
\text { available resources }\end{array}$ & 0 & $\begin{array}{c}3 \\
(12)\end{array}$ & $\begin{array}{c}7 \\
(28)\end{array}$ & $\begin{array}{c}7 \\
(28)\end{array}$ & $\begin{array}{c}8 \\
(32)\end{array}$ \\
\hline Quality & $\begin{array}{l}\text { Overall, the quality requirement and customer } \\
\text { satisfaction will be obtained }\end{array}$ & 0 & 0 & $\begin{array}{c}8 \\
(32)\end{array}$ & $\begin{array}{c}10 \\
(40)\end{array}$ & $\begin{array}{c}7 \\
(28)\end{array}$ \\
\hline
\end{tabular}

\section{Conclusion}

Many software developments have evolved right from 1970's. To overcome the drawbacks of the already existing software developments, agile methodology has evolved to make the work easy for both developers and project teams. Agile uses iterative methods, as these are flexible in nature so it makes the project lightweight. Dynamic changes can also be implemented as per the customer requirement in agile methodology. The main aim of the paper is to describe the agile methodology for software development. From the works of the authors, it was concluded that agile has many benefits when compared to the waterfall model in terms of project success. The main reason for turning the software industries towards the agile methodology for software development is because of its benefits in terms of cost, project delivery and success rate of the project. Industries uses various agile methodologies like XP, Crystal, FDD and scrum as well. Most importantly, agile predicts the man power requirement based on the product complexity and delivery time. The proposed model has a benefit of customer involvement in almost all the stages until the whole project completes. The effectiveness of the proposed model was tested by conducting the survey in three organizations that have an experience in utilizing similar software development models. From the questionnaire, it was understood that the proposed model yields better results in successful completion of the project.

\section{References}

[1]. Cho, J. (2009). A hybrid software development method for large-scale projects: rational unified process with scrum. Issues in Information Systems, 10(2), 340-348.

[2]. Jha, M. M., Vilardell, R. M. F., \& Narayan, J. (2016, August). Scaling agile scrum software development: providing agility and quality to platform development by reducing time to market. In 2016 IEEE 11th international conference on global software engineering (ICGSE) (pp. 84-88). IEEE.

[3]. Mateen, A., Tabassum, M., \& Rehan, A. (2017). Combining agile with traditional $\mathrm{V}$ model for enhancement of maturity in software Development. arXiv preprint arXiv:1702.00126.

[4]. Wright, G. P. (2013). Success rates by software development methodology in information technology project management: A quantitative analysis (Doctoral dissertation, Capella University). 
[5]. Wan, J., \& Wang, R. (2010). Empirical research on critical success factors of agile software process improvement. Journal of Software Engineering and Applications, 3(12), 1131.

[6]. Lindvall, M., Basili, V., Boehm, B., Costa, P., Dangle, K., Shull, F., \& Zelkowitz, M. (2002). Empirical findings in agile methods. InConference on Extreme Programming and Agile Methods (pp. 197207).

[7]. Schwaber, K., \& Beedle, M. (2002). Agile software development with Scrum (Vol. 1). Upper Saddle River: Prentice Hall.

[8]. Ahmed, A., Ahmad, S., Ehsan, N., Mirza, E., \& Sarwar, S. Z. (2010, June). Agile software development: Impact on productivity and quality. In 2010 IEEE International Conference on Management of Innovation \& Technology (pp. 287291). IEEE.

[9]. Lalband, N., \& Kavitha, D. (2019). Software Engineering for Smart Healthcare Applications. International Journal of Innovative Technology and Exploring Engineering, 8(6S4), 325-331.

[10]. Choudhary, B., \& Rakesh, S. K. (2016, February). An approach using agile method for software development. In 2016 International Conference on Innovation and Challenges in Cyber Security (ICICCS-INBUSH) (pp. 155-158). IEEE.

[11]. Wadhwa, M., \& Sharma, N. (2015). Review of agile software development methodologies. Advances in Computer Science and Information Technology, 2(4), 370-374.

[12]. Bahli, B., \& Zeid, E. S. A. (2005, December). The role of knowledge creation in adopting extreme programming model: an empirical study. In 2005 International Conference on Information and Communication Technology (pp. 75-87). IEEE.

[13]. Boehm, B., Port, D., \& Brown, A. W. (2002). Balancing plan-driven and agile methods in software engineering project courses. Computer Science Education, 12(3), 187-195.

[14]. Cockburn, A. (2005). The Methodology Space. Humans and Technology technical report HaT TR, 97.

[15]. Garg, A. (2009). Agile software development. DRDO Science Spectrum, 55-59.

[16]. Report of CHOAS, Retrieved from: http://blog.standishgroup.com/ [accessed: 07 March 2020].
[17]. Layman, L., Williams, L., Damian, D., \& Bures, H. (2006). Essential communication practices for Extreme Programming in a global software development team. Information and software technology, 48(9), 781-794.

[18]. Nguyen, T., Wolf, T., \& Damian, D. (2008, August). Global software development and delay: Does distance still matter?. In 2008 IEEE International Conference on Global Software Engineering (pp. 4554). IEEE.

[19]. Avison, D., \& Fitzgerald, G. (2003). Information systems development: methodologies, techniques and tools. McGraw-Hill.

[20]. Huisman, M., \& Iivari, J. (2003). Systems development methodology use in South Africa. AMCIS 2003 Proceedings, 129.

[21]. Fitzgerald, B. (1998). An empirical investigation into the adoption of systems development methodologies. Information \& Management, 34(6), 317-328.

[22]. Cockburn, A. (2006). Agile software development: the cooperative game. Pearson Education.

[23]. Henderson-Sellers, B. (2003). Method engineering for $\mathrm{OO}$ systems development. Communications of the ACM, 46(10), 73-78.

[24]. Ralyté, J., Deneckère, R., \& Rolland, C. (2003, June). Towards a generic model for situational method engineering. In International Conference on Advanced Information Systems Engineering (pp. 95110). Springer, Berlin, Heidelberg.

[25]. Huisman, M., \& Iivari, J. (2002, May). The individual deployment of systems development methodologies. In International Conference on Advanced Information Systems Engineering (pp. 134150). Springer, Berlin, Heidelberg.

[26]. Gallivan, M. J. (2001). Organizational adoption and assimilation of complex technological innovations: development and application of a new framework. ACM SIGMIS Database: the DATABASE for Advances in Information Systems, 32(3), 51-85.

[27]. Green, G. C., Collins, R. W., \& Hevner, A. R. (2004). Perceived control and the diffusion of software process innovations. The Journal of High Technology Management Research, 15(1), 123-144.

[28]. Velmourougan, S., Dhavachelvan, P., Baskaran, R., \& Ravikumar, B. (2014, September). Software development Life cycle model to build software applications with usability. In 2014 International Conference on Advances in Computing, Communications and Informatics (ICACCI) (pp. 271276). IEEE. 